San Jose State University

SJSU ScholarWorks

Master's Theses

Master's Theses and Graduate Research

1996

\title{
Childrearing practices in Asian Indians, American Asian Indians, and Euro-American parents
}

Deepa Nutan MacPherson

San Jose State University

Follow this and additional works at: https://scholarworks.sjsu.edu/etd_theses

\section{Recommended Citation}

MacPherson, Deepa Nutan, "Childrearing practices in Asian Indians, American Asian Indians, and EuroAmerican parents" (1996). Master's Theses. 1388.

DOI: https://doi.org/10.31979/etd.2p2u-tpav

https://scholarworks.sjsu.edu/etd_theses/1388

This Thesis is brought to you for free and open access by the Master's Theses and Graduate Research at SJSU ScholarWorks. It has been accepted for inclusion in Master's Theses by an authorized administrator of SJSU ScholarWorks. For more information, please contact scholarworks@sjsu.edu. 


\section{INFORMATION TO USERS}

This manuscript has been reproduced from the microfilm master. UMI films the text directly from the original or copy submitted. Thus, some thesis and dissertation copies are in typewriter face, while others may be from any type of computer printer.

The quality of this reproduction is dependent upon the quality of the copy submitted. Broken or indistinct print, colored or poor quality illustrations and photographs, print bleedthrough, substandard margins, and improper alignment can adversely affect reproduction.

In the unlikely event that the author did not send UMI a complete manuscript and there are missing pages, these will be noted. Also, if unauthorized copyright material had to be removed, a note will indicate the deletion.

Oversize materials (e.g., maps, drawings, charts) are reproduced by sectioning the original, beginning at the upper left-hand comer and continuing from left to right in equal sections with small overlaps. Each original is also photographed in one exposure and is included in reduced form at the back of the book.

Photographs included in the original manuscript have been reproduced xerographically in this copy. Higher quality 6" $\times 9$ " black and white photographic prints are available for any photographs or illustrations appearing in this copy for an additional charge. Contact UMI directly to order.

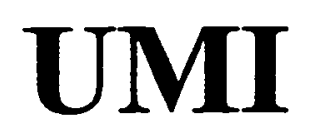

A Bell \& Howell Information Company 300 North Zeeb Road, Ann Arbor MI 48106-1346 USA 

CHILDREARING PRACTICES IN ASIAN INDIANS, AMERICAN ASIAN INDIANS, AND EURO-AMERICAN PARENTS

\author{
A Thesis \\ Presented to \\ The Faculty of the Division of Teacher Education: Child Development Program \\ San Jose State University
}

\author{
In Partial Fulfillment \\ of the Requirements for the Degree \\ Master of Arts
}

by

Deepa Nutan MacPherson

December, 1996 
OMI Number: 1382592

\section{UMI Microform 1382592}

Copyright 1997, by UMI Company. All rights reserved.

This microform edition is protected against unauthorized copying under Title 17, United States Code.

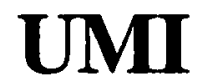

300 North Zeeb Road

Ann Arbor, MI 48103 


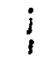

APPROVED FOR THE DIVISION OF TEACHER EDUCATION: CHILD DEVELOPMENT PROGRAM

$\frac{\text { Kathryn O Zxindholm }}{\text { Dr. Kathryn Lindholng }}$
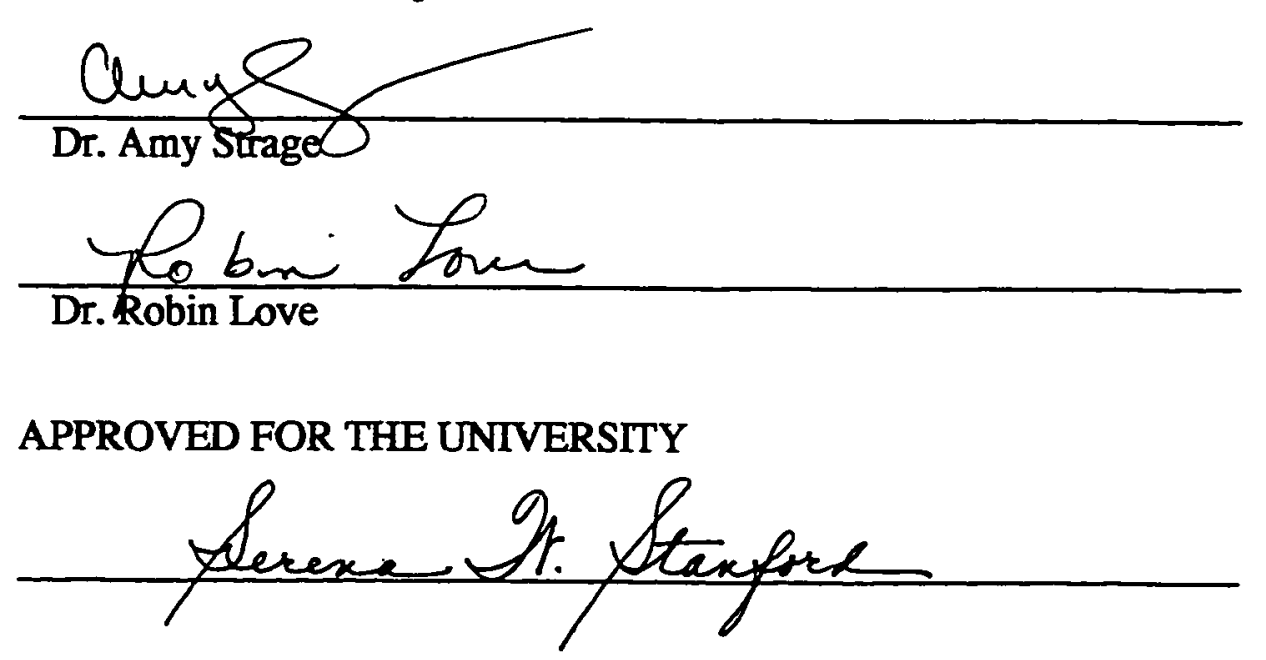
(C) 1996

Deepa Nutan MacPherson

ALL RIGHTS RESERVED 


\section{ABSTRACT \\ CHIIDREARING PRACTICES IN ASIAN INDIANS, AMERICAN ASIAN INDIANS, AND EURO-AMERICAN PARENTS}

by Deepa N. MacPherson

This study examined the differences between Asian Indian, Asian Indian immigrants in the United States, second generation Asian Indians, and Euro-Americans on childrearing attitudes. Parent and child gender was also considered. Parental control, encouragement of independence, emphasis on academic achievement, and nurturance were the specific areas of childrearing that were studied. The study examined 136 subjects who had at least one child between the ages of 5 and 8 . Some ethnic group differences were found in all categories. Euro-American parents were found to be less controlling, to show more encouragement of independence, to emphasize achievement less and to be more nurturing than the other groups in question. There was evidence of acculturation in the areas of parental control and academic achievement. Asian Indians were most controlling and Euro-Americans least controlling. Immigrant Asian Indians emphasized achievement more than any other group. Gender differences were noted in the area of nurturance where fathers showed less affection toward their children than mothers. There were no differences depending on the child's gender. 


\section{ACKNOWLEDGMENTS}

The sincere efforts and patience of my advisor, Dr. Kathryn Lindholm, made the completion of this thesis possible. Thank you to Amy Strage and Robin Love for their willingness to read and contribute to this thesis with such short notice.

A very special thank you to my husband, Robert, who supported me unconditionally through the reseach and writing of this work. A very special thank you to my newborn son, Jason Rajan, for timing his arrival only three days after my oral examination. I love you both.

This thesis is dedicated to my father who allowed me to grow and learn at my own pace and gave me an opportunity to exist within two cultures. In loving memory of my mother who never knew how much my cultural background truly influenced my life. 


\section{TABLE OF CONTENTS}

PAGE

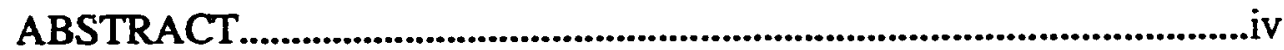

ACKNOWLEDGEMENTS.........................................................................v

TABLE OF CONTENTS..........................................................................

LIST OF TABLES .....................................................................................vii

CHAPTER

I

II

III

IV

$\mathrm{V}$
INTRODUCTION.

Statement of the Problem

Purpose of the Study

Hypotheses

REVIEW OF LITERATURE

Childrearing Practices and Parenting Styles

Theoretical Background

Parenting Styles

The Impact of Culture on Childrearing

Acculturation

Gender Issues

Culture and Gender Influences on Childrearing Practices

Parental Control

Encouragement of Independence

Emphasis on Academic Achievement

Conclusions

METHODS.

. .26

Subjects

Asian Indians in India

Asian Indian Immigrants in the United States

Second Generation Asian Indians in the United States

Instruments

Euro-Americans

Procedures

REFERENCES

APPENDICES 


\section{LIST OF TABLES}

TABLE

PAGE

1.

Levels of Demandingness and Responsiveness in Baumrind's Parenting Styles. 8

2.

Subject Characteristics.............................................................27

3.

Mean Scores and ANOVA Results for Ethnicity and Gender for Parental Control.

4.

Mean Scores and ANOVA Results for Ethnicity and Gender for Encouragement of Independence. .34

5.

Mean Scores and ANOVA Results for Ethnicity and Gender for Emphasis on Achievement.

6.

Mean Scores and ANOVA Results for Ethnicity and Gender for Nurturance. 


\section{Chapter 1}

\section{INTRODUCTION}

Childrearing practices among parents have long interested child development professionals. Beginning with Baldwin's classic study of childrearing in 1948, child development researchers learned that parents could be classified according to various parenting styles. By associating these parenting styles with child outcomes, researchers have begun to understand what childrearing attitudes and behaviors are predictive of more and less successful child development. This information has been vital in assisting child development professionals to teach parents more optimal methods for raising their children. Thus, research aimed at childrearing attitudes has historically been important and continues to provide useful information for optimizing children's development in our society.

As our society becomes more diverse, with individuals from various social, ethnic, and immigrant/generational backgrounds, more research on childrearing attitudes becomes critical. Classic studies have typically only included white middle class populations (Padilla \& Lindholm, 1992).

\section{Statement of the Problem}

Childrearing practices in Asian Indians, American Asian Indians, and EuropeanAmericans tend to differ based on varying traditions and values. There is little information on Asian Indian childrearing practices and considerably less on immigrant Asian Indians. In contrast, a large amount of literature is available on Euro-American childrearing practices. This information is crucial for the field of child development in order to bridge cultural gaps between the dominant culture with the culture of immigrant Asian Indians. In addition, child development professionals should have access to as much information as possible about various cultural childrearing practices in order to understand childrearing expectations of a variety of parents. With the rise in Asian 
Indian immigration to the United States it is important to consider this culture and add to the body of knowledge in the area of childrearing practices and generational change.

There are similarities between various Asian cultures and the Asian Indian culture. Therefore, considering studies on Asian cultures can serve as a starting point for a study on Asian Indian childrearing practices. The present study is a replication of a study conducted by Lin and Fu (1991) which focused on childrearing practices of Chinese, immigrant Chinese, and Caucasian mothers and fathers. The goal of their study was to examine differences in attitudes on childrearing practices as Chinese parents immigrated to the United States and how similar the attitudes were to Caucasian or Chinese parents.

Traditionally, when considering childrearing practices only maternal behaviors were used for data analysis. Currently, it is important to consider the input of both mother and father. There is an increasing number of dual income families in our society which has led to a more androgenous situation for childrearing. In other words, more fathers are taking an active role in raising their children. The study by Lin and Fu (1991) also used data from both parents.

The categories of study used by Lin and Fu (1991) were parental control, encouragement of independence, emphasis on academic achievement, and nurturance. These categories were carefully selected by Lin and Fu after a review of Confusian principles and other studies on Asian culture. Previous studies had suggested that there were differences in these childrearing categories between Asian and Euro-American parents (Engel, 1984; Suzuki, 1980).

Purpose of the study

The present study was a replication of Lin and Fu's (1991) study, but with a sample of Asian Indians. The present study also considered further generational change by examining the attitudes of second generation immigrant Asian Indians. Thus, the 
purpose of this study was to determine whether Asian Indians, first generation Asian Indian immigrants, second generation Asian Indian immigrants, and Caucasian Americans differ in their attitudes toward parental control, encouragement of independence, emphasis on academic achievement, and nurturance. Another purpose was to examine if mothers and fathers would vary in their attitudes, or whether their attitudes would differ as a function of their child's gender.

\section{Hypotheses}

This study has several hypotheses that address the various childrearing categories and samples of subjects. The hypotheses are based on the study done by Lin and Fu (1991) which focused on the same childrearing categories for their Chinese subjects, although Lin and Fu's study did not incorporate the second generation subjects as in the present study.

The first hypothesis is that Asian Indians will show the strongest levels of parental control, followed by immigrant Asian Indians, then second generation Asian Indians, and finally Euro-Americans. A second hypothesis is that fathers in all groups will score higher in parental control than mothers. Finally, it is hypothesized that parents will show stronger levels of control when their children are female.

In the category of encouragement of independence, the hypothesis is that Asian Indians will score lower than immigrant Asian Indians, who will score lower than second generation Asian Indians, who will score lower than Euro-Americans. Further, fathers will show stonger levels of encouragement of independence that mothers. In addition, parents will encourage independence more for their sons than daughters.

For emphasis on academic achievement, the hypothesis is that Asian Indians will score higher than immigrant Asian Indians, who will score higher than second generation Asian Indians, who will score higher than Euro-Americans. In addition, another 
hypothesis is that fathers will emphasize achievement more than mothers, and emphasis on academic achievement will be higher for sons.

The hypothesis for the category of nurturance is that Asian Indians will score lower than immigrant Asian Indians, who will score lower than second generation Asian Indians, who will score lower than Euro-Americans. Additionally, it is hypothesized that fathers will show lower levels of nurturance than mothers. Futhermore, parents will show less nurturance toward their sons than daughters. 


\section{Chapter 2}

\section{REVIEW OF LITERATURE \\ Childrearing Practices and Parenting Styles \\ Theoretical Background}

Much of the present knowledge of childrearing practices and parenting styles has followed the framework of early research which identified various categories of childrearing. One classic study that helped set the stage for the study of childrearing practices was conducted by Baldwin (1948) who based his research on observations at a school nursery and home visits. He used behavioral rating scales which included factors such as affectionateness, nonconformity, impatience, disobedience, curiosity, competitiveness, quarrelsomeness, and leadership. Through intercorrelations of these variables, he was able to identify two major childrearing dimensions: control and democracy. Control is defined as having clear restrictions for a child where occurrences of friction over discipline are rare. Democracy refers to having open communication with a child where reasons are offered along with decisions and where mutual agreements occur between parent and child.

Democracy and control are not mutually exclusive; in fact, they are best understood when they are considered as an interaction. When a parent is high on control, but low on democracy, there is little or no discussion between parent and child regarding decisions. Since restrictions are made very clear there is seldom any confusion over the expectations of a child. The questioning of parental authority is not tolerated and high levels of conformity are required. According to Baldwin, children of parents high on control and low on democracy are conforming, obedient, quiet, and well-behaved. They are typically not quarrelsome, planful, tenacious, or fearless.

In comparison, Baldwin's (1948) study suggests that parents who are high on democracy and low on control have much verbal contact with their children, which 
includes explanations for parental actions and discussions to satisfy the child's curiosity. This verbal contact decreases any confusion or arbitrariness regarding parental decisions. Baldwin describes children of parents high in democracy and low on control as active, fearless, and curious. However, these children may also lack discipline, and be more cruel than an average child.

The combination of low control and low democracy is evident when parents have few restrictions on their children and communication is infrequent and casual. Parents do not play a leader's role in discussions and there is generally little interaction between parent and child in the home. Children raised in uncontrolled, undemocratic homes are detached from their parents, show little affection, and lack independence.

Of all the possible combinations of control and democracy, Baldwin describes high democracy and high control as the optimal situation. These parents tend not to infringe on the personal freedom of their children which allows them a degree of independence. They also encourage some conformity and require their children to be socially responsible. This combination results in a planful, inventive child who participates in his or her own socialization.

Following on Baldwin's work, Baumrind $(1967,1973,1977)$ has done extensive research on parenting dimensions and styles that have been very influential in the study of childrearing. She considered two dimensions of parental behavior: demandingness and responsiveness which are related to Baldwin's control and democracy, respectively. Demandingness refers to the amount of control a parent exerts over a child, as in Baldwin's dimension of control, and encompasses the expectations that parents have for their children to excel cognitively, emotionally, and socially. A highly demanding parent will have clear, strict expectations of a child, whereas a less demanding parent will have fewer expectations of a child. Responsiveness is defined as the levels of acceptance and warmth a parent offers a child, similar to Baldwin's democracy. A highly responsive 
parent will offer a great deal of acceptance and warmth, and parent-child issues are more child-centered. In contrast, a low responsive parent will be more rejecting of the child and show little warmth, and parent-child issues are considerably more parent-centered (Baumrind, 1967).

The parenting dimensions of control/democracy and demandingness/ responsiveness described by Baldwin and Baumrind are central theoretical constructs in current research on parenting strategies, and in the influence of various parenting styles on child and adolescent development. By comparing different levels of demandingness and responsiveness, Baumrind and others (e.g., Baldwin, 1948; Baumrind \& Black, 1967; Dombusch, Ritter, Leiderman, Roberts, \& Fraleigh, 1987; Lamborn, Mounts, Steinberg, \& Dornbusch, 1991) have considered different parenting styles in their research. Although the research that has been reviewed here has been very influential in the study of parenting, it is important to consider the specific research that has shaped our body of knowledge on parenting styles.

\section{Parenting Styles}

Baumrind's (1979) parenting styles were derived by interacting low and high levels of demandingness and responsiveness, as shown in Table 1. High levels of demandingness and low levels of responsiveness are associated with authoritarian parenting, whereas high levels of demandingness and high levels of responsiveness are related to authoritative parenting. Permissive parenting is defined by low levels of demandingness and high levels of responsiveness. 
Table 1

Levels of Demandingness and Responsiveness in Baumrind's Parenting Styles

\begin{tabular}{|c|c|c|c|}
\hline & Authoritarian & Authoritative & Permissive \\
\hline Demandingness & + & + & - \\
\hline Responsiveness & - & + & + \\
\hline
\end{tabular}

In authoritarian parenting, there is a clear desire for children to be obedient and respectful of authority; little responsibility is given to the child for making personal decisions, and they are not often consulted on family decisions; and there is a clear desire for children to be obedient and respectful of authority. Early studies suggested that the children of authoritarian parents showed little independence, were unhappy and socially withdrawn, and were only adequate in social responsibility (Baumrind, 1967; Baumrind \& Black, 1967).

Many studies have supported the child outcomes of authoritarian parenting that Baumrind found in her research. Studies have suggested that children of parents high in control and low in democracy, authoritarian parents, were obedient and conforming (Baldwin, 1948; Lamborn et al., 1991); aggressive (Maccoby \& Martin, 1983); lacked curiosity, tenacity, and originality; and were not not quarrelsome, resistant, or very independent (Baldwin, 1948). Academically, children of authoritarian parents do not score as high as children of authoritative parents (Dombusch et al., 1987). Authoritarian parenting can also affect moral development which is evidenced through studies by Hoffman (1970) and Salzstein (1976), which suggest that children who have an external moral orientation are more likely to have authoritarian parents. This parenting style is also related to low self-esteem, poor self-concept, and external locus of control (Coopersmith, 1967; Lamborn et al., 1991; Loeb, Horst, \& Horton, 1980). 
As Table 1 shows, permissive parenting is characterized as the opposite of authoritarian; that is, low in demandingness and high in responsiveness. Permissive parents appeal to a child's sense of reasoning rather than using authority, status, physical strengths, or rewards and punishments to control their children. They are rarely demanding of their children, but are warm and accepting of their children's impulses, desires, and actions. Children of permissive parents may lack independence, responsibility, and impulse control and at the same time be aggressive (Baumrind, 1967; Baumrind \& Black, 1967; Maccoby \& Martin, 1983; Olweus, 1980). In addition, permissive parents do not have high expectations which results in poorer academic achievement (Dornbusch et al., 1987; Maccoby \& Martin, 1983).

Authoritative parenting is high in both demandingness and responsiveness (see Table 1). Parents use firm control, encourage rational discussions and independence, expect responsibility, and respect the rights of their children. Authoritative parents set standards but explain their decisions in establishing expectations. They are also accepting of and affectionate with their children. Many studies have linked authoritative parenting with positive child outcomes such as: high self-esteem (Coopersmith, 1967; Loeb et al., 1980); high levels of social responsibility, self-assertion, and independence (Baumrind, 1967, Baumrind \& Black, 1967; Maccoby \& Martin, 1983); and high academic grades for adolescents (Dornbusch et al., 1987).

The importance of considering various aspects of parental behavior is central to most theories that have been influential in the study of parenting. The studies by both Baumrind and Baldwin reviewed here stress that high control and/or demandingness are essential in order to insure positive outcomes of parenting for children. Both theorists suggest that control/demandingess alone do not result in positive outcomes, but must be accompanied with high level of democracy/responsiveness. The degree to which parents 
employ these two dimensions in their childrearing attitudes depends on many factors including culture, gender, and generation.

Although the research presented in the past two sections has presented the theoretical background of parenting, much of the literature lacks a culturally diverse perspective, as most of the research has been conducted with white middle class parents and children (Padilla \& Lindholm, 1995). Because of the cultural diversity represented in the United States, cultural issues must be examined in order to accurately study issues of parenting and childrearing in our society.

The Impact of Culture on Childrearing

The theoretical framework outlined so far in this review explores various dimensions of childrearing and parenting. However, it lacks any discussion of how culture may influence parenting strategies. Despite the important influence of culture on childrearing, most theories of childrearing have not incorporated culture, and most childrearing studies have not included ethnic minority subjects (Bronfenbrenner, 1979; Graham, 1992; Levine, 1974; Padilla \& Lindholm, 1995; Spencer \& Dornbusch, 1990). The reason culture is important in childrearing is that the socialization process involves inculcating in the child the norms and values of society. However, norms and values are contextualized by culture; what may be appropriate for one culture may be considered inappropriate for another culture. For example, dating before marriage is a widely accepted phenomenon in the Euro-American culture (Skipper \& Noss, 1966). However, in traditional Chinese culture, dating before marriage is not accepted. In fact, parents pre-arrange their children's marriages sometimes without the child's input (Engel, 1984). In this example, children in traditional China are socialized to follow their parents' judgement on marriage, whereas American children are socialized to follow their own judgement. 
Levine (1988) presents a cultural evolutionary position wherein parents combine cultural standards with personal factors in selecting childrearing methods. Parents internalize cultural norms, but choose methods of raising children which match their needs and resources. This method of childrearing may be more prevalent in societies rich in cultural diversity or industrialized societies where cultural forces vary. For example, a given culture may dictate that education is essential in a child's life, but if the parents are struggling to provide food for their children, education may not be as high a priority. The remainder of this section will briefly portray the importance of culture in childrearing.

Chinese culture has been strongly influenced by ancient Confucian principles, which have important implications for childrearing. Confucianism suggests that appropriate parent-child interactions are based on the following elements: parental control, child obedience, strict discipline, emphasis on education, filial piety, respect for elders, family obligations, and respect for traditions (Chao, 1983). In addition, Chinese culture incorporates collectivism; the needs of the family and social units supercede the needs of the individual (Suzuki, 1980). Chinese culture focuses strongly on formal education. Children are taught at a young age that personal success will depend on academic achievement (Chen \& Uttal, 1988; Ho, 1981). Children are also encouraged to maintain internal goals of achievement, conformity, and family loyalty which are all central to the Confucian society.

Much like the Chinese, Asian Indians are influenced heavily by their culture. Traditions, folklore, and rituals give Asian Indian culture a foundation for its values and standards. The traditional epic, Ramayana, written over a century ago, has been very influential in formulating the Asian Indian philosophies of life. The Ramayana is a series of stories where a prince, Rama, encounters several situations where morality and ethics are challenged. Each story ends with a message. For example, it is believed that children should always respect the wishes of an elder, regardless of how the elder's wishes will 
affect the child. In one particular story, Rama is ordered by his stepmother to take a long journey so that her own son, the next heir to the throne after Rama, will become King instead of Rama. Even though Rama is aware of her plans, he leaves town. Although the stepmother's actions may be considered wrong or undesirable to Rama, he still obeys her wishes because she is an elder and he knows he is expected to follow her wishes (Rajagopalachari, 1973). Other values emphasized in the Ramayana that indicate how children should be raised in Asian Indian culture are: emphasis on family bonds, loyalty, obedience, and achievement (Kakar, 1978). More recent studies suggest that Asian Indians tend to be achievement oriented, discourage autonomy, emphasize the extended family, and focus on obedience, and respect for elders (Dasgupta, 1989; Helwig \& Helwig, 1980; Wakil, Siddique, \& Wakil, 1981).

The Euro-American culture differs from the Chinese and Asian Indian cultures in several distinctive ways. First, the Euro-American parent-child relationship is based on discussion and mutual agreements rather than parental control (Maccoby \& Martin, 1983), as in Chinese and Asian Indian cultures. Second, Euro-American values are individually oriented as opposed to the group oriented values favored by Chinese and Asian Indian. Euro-American parents encourage their children to be physically and emotionally separated from them and parents value individual development in their children (Jung, 1984; Steinberg \& Silverberg, 1986). For example, children are encouraged to utilize self-help skills at a young age rather than learning to depend on a member of the family (Alwin, 1988; Whiting \& Child, 1953), which would be more appropriate in Chinese and Asian Indian families.

Research with African American, Hispanic, Japanese, and Arabic families also show the important influence of culture on childrearing (e.g., Hale-Benson, 1982; Madanipour, 1977; Martinez, 1993; Ogbu, 1985; Ramirez, 1989; Vega, Hough, \& Romero, 1983; Yamamoto \& Kubota, 1983). It is clear that families within a particular 
cultural subgroup also vary in their childrearing practices (Padilla \& Lindholm, 1995). Factors such as socioeconomic status, religious values and orientations, and generation of residence in the United States impact families within various subgroups (Lindholm, 1981; Maccoby \& Martin, 1983; Padilla \& Lindholm, 1995) One variable that has been only sparsely examined with respect to childrearing practices is generation of residence, or acculturation to the United States' dominant culture.

\section{Acculturation}

Acculturation is a process that occurs when two or more cultures come in contact with each other and the behaviors of members of one culture change toward the standards of the host culture (Berry, 1980; Mena, Padilla, \& Maldonado, 1987; Padilla, 1980). Berry (1980) describes a three-phase course to acculturation. The first step of acculturation is contact which can be equated with the actual immigration. The family goes through an orientation phase where members are introduced to new ways of life, such as educational systems, housing constructs, and expectations on children. The second step is conflict which is seen when first generation immigrants try to incorporate their original ways of life with the new ways of the host culture. An example of this conflict is the desire for children of immigrants to date when it is not acceptable in the native culture. The final step is adaptation which occurs in one of two forms: assimilation or multiculturism. Assimilation refers to a family's incorporation of the norms and standards of the host culture along with some devaluation of the native culture. Multiculturism refers to a situation in which families are able to incorporate a mix between the two cultures, valuing both in varying degrees. This cultural adaptation may not be apparent in first generation immigrants who often depend on their traditional cultural values and norms. However, families of second and third generation immigrants show stronger signs of assimilation than their first generation ancestors. 
Some studies on the influence of acculturation and generational change on childrearing have been conducted (Caudill \& Frost, 1973; Feldman \& Rosenthal, 1990; Ghaffarian, 1987; Lin \& Fu, 1991; Lindholm, 1981; Madanipour, 1977; Patel, Power, \& Bhavnagri, 1996; Rosenthal \& Feldman, 1990; Steward \& Steward, 1973). Results from many of these studies show that there is indeed an effect of acculturation on childrearing practices. Madanipour's (1977) study suggests that Iranian mothers in the United States promote more independence and are more responsive to their children than Iranian mothers in Iran. In addition, Caudill and Frost (1973) found that acculturation influences the parenting practices of first and later generation Japanese American mothers. In their study, later generation Japanese American mothers behaved more similarly to their American counterparts than did first generation Japanese American mothers. Patel et al. (1996) found that immigrant Indian fathers showed change from traditional values toward daughters depending on modernity, acculturation, and time in the United States. Evidence of generational change in immigrant families was also found by Lin and $\mathrm{Fu}$ (1991). Their study suggests that there is some change in childrearing attitudes from collectivism to individualism even in the first generation Chinese immigrants in areas such as parental control and encouragement of independence. First generation parents scored lower on parental control and higher on encouragement of independence than Chinese parents.

The degree of generational change that is seen in these studies depends on many factors. These factors include gender of the parent and child, socioeconomic status, education level, and age of the children ( $\mathrm{Lin} \& \mathrm{Fu}, 1991)$. Moreover, there is a desire for immigrant parents to instill traditional values in their second generation children. Parents often struggle to find a medium between traditional values and assimilation (Saran, 1985). The present study adds to this body of literature by considering the generational 
change of attitudes regarding childrearing in Asian Indians in India, and first and second generation populations of Asian Indians in the United States.

\section{Gender Issues}

Much of the literature on childrearing practices is based on reports from mothers (Lamb, 1981; Maccoby \& Martin, 1983; Sears, Maccoby, \& Levin, 1957). Researchers have had difficulty finding fathers to participate in studies in part due to work schedules (Maccoby \& Martin, 1983). There has historically been a tendency for mothers to be more available to participate in research studies since they are typically primary caregivers. It has been difficult to get accurate, reliable information on father-child relations based on childrearing practices (Maccoby \& Martin, 1983). In addition, evidence suggests that there is less interaction between father and child than between mother and child (Kotelchuck, 1972).

Many Asian, Asian Indian, Hispanic, and African American families rely heavily on the mother for childcare and childrearing. Fathers in these cultures tend to be less involved with childrearing because gender roles are more well defined with mothers being primary caregivers and fathers being primary providers (Chao, 1983; Kakar, 1978; Ogbu, 1985; Ramu, 1977; Vega, Hough, \& Romero, 1983). In recent years the EuroAmerican culture as well as some acculturated ethnic groups have slowly become more androgynous with regards to roles in the household. Parents are now sharing more responsibility in the home including childrearing and caregiving (Santrock, 1990). With this shift in attitude regarding traditional male and female roles, it is important to consider childrearing strategies of both mother and father.

Studies of fathers have been more recently introduced in the field of child development, however there are still limitations. There are still very few studies that incorporate paternal input. Many of the studies that are strongly influential in the area of childrearing do not include fathers in the subject pool. There is a strong need for more 
information on father-child relationships in child development. The present study will consider the difference in attitudes on childrearing between mothers and fathers.

Culture and Gender Influences on Childrearing Practices

There is a large body of research that examines the individual childrearing strategies that parents employ. While works of early theorists such as Baldwin or Baumrind focused on describing parenting styles used by parents (i.e., control, democracy, authoritarian, authoritative), other studies have examined relationships between individual childrearing strategies and children's cognitive, social, emotional, and moral development (for a review, see Damon, 1983; Maccoby, 1980; Maccoby \& Martin, 1983).

Since norms and standards differ from culture to culture it is important to consider various cultural and acculturation differences in childrearing. The present study focuses on the childrearing practices of: parental control, encouragement of independence, emphasis on academic achievement, and nurturance. These are the childrearing practices studied by Lin and Fu (1990), of which this study is a replication. Therefore, the review here will be limited to those studies that have provided information pertinent to these themes and how they are influenced by culture and gender.

\section{Parental Control}

As discussed earlier, the strategy of control is an important component of Baumrind's parenting styles and Baldwin's combination of control and democracy. However, research shows that it is the type of control utilized by parents that makes control an effective or ineffective strategy in childrearing. Maccoby (1980) has proposed five definitions of control: restrictiveness, demandingness, strictness, intrusiveness, and arbitrary exercise of power. Each of these definitions will be expanded upon and then examples of child outcomes will be described. 
Restrictiveness refers to the consistent enforcement of rules without allowing children to divert their parents from those rules. Numerous studies have found relationships between restrictiveness and positive child outcomes, such as: showing the ability to control impulses (Patterson, 1976); being adequately controlled rather than undercontrolled or overcontrolled (Block, 1971); having high self-esteem (Coopersmith, 1967); and the ability to take initiative in tasks, and having a positive mood (Baumrind, $1967,1971,1977)$. When control is defined as restrictiveness, outcomes seem to be positive.

Levels of demandingness which refers to a parent's expectation for a child to have more responsibility than the child may be ready to accept. Parents high in demandingness may have children who are: low in aggression (Edwards \& Whiting, 1977), altruistic (Whiting \& Whiting, 1973), and be above average in competence (Baumrind, 1967, 1971, 1977). Low levels of demandingness can result in high aggression (Sears, Maccoby, \& Levin, 1957), uncontrollable impulses (Block, 1971), and immaturity (Baumrind, 1967, 1971, 1977). The positive effects of high demandingness are only evident when the child has the ability to meet the demand and when the demand is made with parental support (Maccoby, 1980). These findings are consistent with the positive outcomes of Baumrind's (1977) authoritative parenting which incorporate high levels of demandingness along with high levels of responsiveness.

Strictness is the enforcement of rules with little flexibility to children's attempts to question or challenge the rules. Strictness can have favorable effects on children depending on the level of warmth that accompanies it (Maccoby, 1980). In order for strictness to be considered a positive definition of control, it should be accompanied by warmth. Becker (1964) suggested that children of strict but warm parents were obedient, polite, and unaggressive. However, strictness paired with hostility can result in a timid child who lacks tenacity (Baldwin, 1948). When warmth is minimal and strictness is 
high, a pattern similar to Baumrind's authoritarian parenting exists along with the associated negative outcomes discussed previously.

Intrusiveness refers to parents interfering in children's plans and relationships. Arbitrary power assertion is setting rules and requirements and enforcing them with little explanation to the child. If control is defined in these way, it can result in the following outcomes: lack of empathy (Feshbach, 1974), low self-esteem (Coopersmith, 1967), sad moods, a withdrawn disposition (Baumrind, 1967, 1971, 1973, 1977), and a lack of independence (Baumrind, 1971). On the other hand, open communication which allows for setting rules and requirements, but offering explanations along side these demands, results in children who are competent, independent, and socially responsible (Baumrind, 1967, 1971), planful and fearless (Baldwin, 1948), and high in self-esteem (Coopersmith, 1967).

Since control can be defined in so many different ways, it is important to understand how it is being defined before categorizing it as negative or positive. This research demonstrates how parental control paired with some level of nurturance renders positive outcomes in children. From the literature that has been reviewed, control can be considered authoritarian if parents are restrictive, demanding, strict, and intrusive; but lack high degrees of nurturance; and use arbitrary power assertion in setting rules and limits. On the other hand, control can be defined as authoritative if restrictiveness, demandingness, and strictness are used with nurturance. In addition, authoritative parents will seldom be intrusive, but will often use explanations when setting rules and limits.

In Asian culture, as defined in the Confusian principles, parental control is highly regarded (Chao, 1983). Children have little decision making power in the family and usually are expected to follow the decisions made by the parents for themselves. Thus, authoritarian control as described by Baumrind (1977) and Maccoby (1980) is the norm in Asian cultures. Most Asian parents are controlling, with fathers being more 
controlling than mothers, who tend to be more indulgent and nurturing (Huang \& Ying, 1989). This is exemplified in Lin and Fu (1991) where Chinese mothers and fathers scored higher on parental control than immigrant Chinese parents who scored much higher than Caucasian parents.

There is a tendency for fathers to exert more control over children than mothers (Lamb, 1981; Lin \& Fu, 1991). Lin and Fu found that immigrant Chinese fathers and Caucasian fathers scored higher in areas of parental control than mothers in both these groups. Even though the use of authoritarian parental control as a childrearing practice may be a widely accepted norm in Asian cultures, it may also be a widely accepted norm for fathers over a wide range of cultures.

\section{Encouragement of Independence}

Encouragement of independence is a childrearing strategy seen mostly in parents who are authoritative or permissive (Baumrind, 1977). It is seldom seen in authoritarian parents since they tend to be so controlling that children are not given the opportunity to be independent. When parents support children's autonomy, independence will be encouraged. Autonomy exists when parents employ parenting techniques which facilitate independent decision-making, problem-solving, and offer choices. Supporting autonomy allows children to learn self-regulation and self-monitoring (Baldwin, 1948). Studies suggest that children of parents who encourage autonomy experience positive outcomes such as high grades and high self-esteem (Damon, 1983; Grolnick \& Ryan, 1989). Because these studies incorporate predominantly Caucasian populations, there is a need to consider encouragement of independence in various cultures.

Feldman and Rosenthal (1991) describe two different philosophies of society which influence a family's values toward in(ter)dependence: collectivism and individualism. The Euro-American society employs individualism which encourages independence and autonomy. In this context, the individual strives for the well-being of 
self. On the other hand, many Asian and Hispanic subgroups exercise collectivism, where there is an emphasis on the well-being of the group over the individual so interdependency is fostered. This is not only evident in society-at-large but also within the family unit. How individualism and collectivism are practiced in the home will be described next.

The literature on the encouragement of independence suggests that independence is promoted through specific parental attitudes and behaviors that are also valued by society. When these values of individualism are not supported by society parents will not encourage autonomy and will focus on interdependency. For example, the studies on Taiwanese value systems suggest that independence is not encouraged in children, and that frequent giving and receiving between generations is expected. In fact, children's earnings are often shared with the extended family (Grichting, 1970). The same scenario is seen in Hispanic families where reciprocity is a focal point in the family. Reciprocity is defined as the give and take between two people when one is in reed and the other is in a position to give. This reciprocity is evident when parents provide financial support for their children and then later children come to assist parents when they are in need, such as old age (Vega, Hough, \& Romero, 1983). Similarly, in traditional Asian Indian families, the focus is not on the individual, but on the family unit. Children do not strive for independence nor is it necessarily encouraged. Because living spaces are small and families live in close proximity, individuation is neither feasible or desirable. In addition, family interdependency is a way of life and independence is equated with loneliness (Saran, 1985).

Children in India are conditioned from their early years to prepare for their roles as adults. Boys traditionally stay with their parents all their lives. The eldest boy is prepared to take over as the head of household and the younger boys are prepared to take on various roles to support the extended family unit such as working outside the home for 
family income (Ramu, 1977; Roland, 1988). Girls are prepared to support the family of their future spouses by being exposed to household tasks, childrearing, caring for the husband, and food preparation (Kakar, 1978; Ramu, 1977; Roopnarine \& Hossain, 1992). Due to the difference in future roles boys are given more freedom in childhood than girls. In addition, parents in India fear that daughters who are given too much freedom will experience difficulty in finding a suitable husband because society may label girls with too much freedom as promiscuous (Roland, 1988).

The views on independence in Asian Indian families and families of other cultures described above are contrary to the views of families in the Euro-American society. Euro-American families place high value on independence. Children are socialized to lead separate lives apart from their parents especially during the adolescent years. In early adulthood, Euro-Americans are encouraged to support themselves financially, emotionally, and physically (Sussman, 1953).

The definition of independence is very important. Lin and Fu (1991) found that Chinese subjects may not define independence as American subjects may. This difference in interpretation may be due to the operational function of dependency in China as opposed to the United States. Chinese culture incorporates collectivism where family interpendency is necessary for social development. However, social development in the United States depends on individuation where independence is essential.

\section{Emphasis on Academic Achievement}

Emphasis on academic achievement refers to the extent to which parents value educational success. Academic achievement is based on three components: intelligence, factors in the educational setting, and factors in the family (Stevenson \& Lee, 1990). Academic achievement has been studied in great detail. Recent studies consider the relationship between achievement and the parenting styles identified by Baumrind (1967). Considerable research suggests that emphasis on academic achievement is 
related to the parenting styles (e.g., authoritarian, authoritative, and permissive) utilized by parents (Dombusch et al., 1987; Grolnick \& Ryan, 1989; Lamborn et al., 1991; Steinberg, Mounts, Lamborn, \& Dornbusch, 1991). Studies suggest that authoritative parenting is strongly associated with high academic achievement, whereas authoritarian and permissive parenting is negatively associated with achievement. However, we must consider the values of various cultures before relating parenting styles to achievement.

Dombusch et al. (1987) found associations between adolescents' grades in school and parenting styles. Positive correlations were found between authoritative parenting and high grades. In contrast, authoritarian and permissive parenting were negatively correlated with grades. However, results differed somewhat by ethnicity. Asian students had the highest grades, yet many of them came from authoritarian households. However, in examining the Asian students, Dornbusch et al. (1987) found a positive correlation between authoritarian parenting and grades, but at the same time found even higher correlations between authoritative parenting and grades. This conclusion implies that, at least for Asian students, high grades can result from authoritarian parenting. Among Hispanic students grades were negatively correlated with authoritarian parenting, with daughters of authoritarian parents having a stronger negative correlation than sons. These conclusions suggest the need to add cultural diversity to our understanding of the influence of parenting styles on academic achievement.

Children of Euro-American parents are encouraged to achieve academically, but typically the encouragement differs from that of Asian parents (Grolnick \& Ryan, 1989). Grolnick and Ryan (1989) suggest that academic success is related to: clarity of parental expectations, consistency in interactions, parental awareness of children's behaviors, and the amount of enjoyable time spent with a child. They also found a relationship between a child's sense of control over his/her academic setting and the existence of a predictable structure in the home. 
Lin and Fu (1991) found that Chinese parents showed stronger emphasis on academic achievement toward their offspring than did immigrant Chinese parents who in turn showed more emphasis than Caucasian-American parents. The researchers suggest that traditional Confucian values of attaining high academic success are attributed to this childrearing attitude in Chinese parents. This tradition is passed through generations and is found in immigrants in the United States as well.

Similar to Asian families, Asian Indian families hold high expectations for academic achievement (Kishor, 1983; Segal, 1991). Many times, children will be excused from familial duties for the sake of studying in order to achieve. In India, a child raised in a middle to upper class family must focus primarily on studying and striving for high levels of academic achievement (Saran, 1985). There is a belief that academic achievement will lead to success in the future. Parents depend on their children's success because traditionally parents are taken care of by their children when they become elderly (Roland, 1988).

\section{Nurturance}

The childrearing strategy of nurturance is one of the basic elements of Baldwin's democracy (1948) and Baumrind's responsiveness $(1967,1971)$. Without nurturance, neither dimension would have positive effects on children. Nurturance is related to secure attachments (Ainsworth \& Bell, 1969; Ainsworth, Bell, \& Stayton, 1971; ClarkeStewart, 1973), compliance (Patterson, 1976), high self-esteem (Coopersmith, 1967), and overall effective parenting (Maccoby \& Martin, 1983). However, nurturance alone does not guarantee positive outcomes; it must be paired with some degree of control (Maccoby \& Martin, 1983). As seen in each strategy described above, cultural diversity issues must be considered.

Descriptions of affection in Asian Indian parent-child relations are made by Kakar (1978). He describes Asian Indian mothers as indulgent, they are in constant close 
contact with their infants. This contact lasts past infancy and the mother is characterized as highly accessible to the child most of time. Sometimes children are the dominant party in a mother-child dyad (Kakar, 1978). On the other hand, Kakar (1978) describes the Asian Indian father as dominant; his role as the authority figure brings about fear from his children.

Work done by Roopnarine et al. (1990) shows that urban Asian Indian mothers in New Delhi were more likely to hold their infants, feed and play with them, and give comfort to them than were fathers. In addition there was some evidence of resistance from the fathers to participate in caregiving. These findings add support to Kakar's (1978) descriptions of mother and father roles in India presented previously. Gender roles are passed through generations through the socialization process (Salgado de Snyder, Lopez, \& Padilla, 1982).

Lin and Fu (1991) considered affection in their study comparing Chinese, immigrant Chinese and Caucasian American parents' beliefs in childrearing. They chose to consider this variable because of traditional Confucian values that suggest Chinese families will be stronger if displays of affection are kept to a minimum (Bond \& Wang, 1983). In addition, fathers typically were emotionally removed from their children and this type of relationship was left up to the mother (Hsu, 1981). Lin and Fu did not find a difference between parent attitudes in the three groups considered.

\section{Conclusions}

Most of the literature described here focuses on cultural differences in the first generation. There is a lack of information on generational change in attitudes on childrearing in immigrants in the United States. This change is important in considering how generations of families of various cultures move through the acculturation process and what degrees of assimilation or multiculturism are incorporated. In addition, it is 
important to consider how acculturation influences the childrearing practices of future generations.

There is also a lack of information on gender diffences in parental attitudes on childrearing between mothers and fathers of all backgrounds. In addition, it is important to consider how the gender of a child influences childrearing attitudes. The present study incorporates child's gender in data analysis. This information will allow child development professionals to view various parenting styles and childrearing practices based on child's gender in addition to gender of the parent.

The present study considered how acculturation influences attitudes on childrearing by comparing attitudes of Asian Indians in India, first generation immigrant Asian Indians, second generation Asian Indian, and Euro-Americans. At the same time, this study examined the effects related to the gender of the parent and the gender of the child on childrearing attitudes. If immigrant families do assimilate to Euro-American norms, later generation immigrants will have attitudes more similar to Euro-Americans than to their ancestors in their native lands. 


\section{Chapter 3}

\section{METHODS}

Subjects

There were 68 couples, for a total of 136 subjects, surveyed in this study. Subject background information is presented in Table 2 . As Table 2 shows, forty subjects (20 fathers and 20 mothers) were Asian Indians in India; 34 subjects (17 fathers and 17 mothers) were first generation immigrant Asian Indians living in the United States; 22 subjects (11 mothers and 11 fathers) were second generation American Asian Indians, and 40 subjects ( 20 mothers and 20 fathers) were Euro-Americans. The subjects were married couples with at least one child between the ages of five and eight. Each spouse served as a separate subject. The families were predominantly educated professionals in both the United States and India. Ninety three percent of all subjects held at least a four year degree and $81 \%$ of the subjects were employed. Since the questionnaire was prepared in English, all subjects were required to be proficient in English. This requirement also served to ensure a high level of education in the Asian Indian group in India.

\section{Asian Indians in India}

Asian Indians in India were selected from a population of parents in two apartment complexes in Bombay, India: Kshatriya Nivas No. 1 and No. 8. The limitation of two apartment complexes in Bombay ensures consistency in living conditions and socioeconomic status among the subjects. The city of Bombay was selected because of the diversity of Indian subcultures in Bombay, for example: Maharashtrians, Gujratis, Panjabis and Sikhs. There were 20 father subjects in this group: $100 \%$ of them were employed and $90 \%$ of them held a college degree. Of the 20 mother subjects in this group, $70 \%$ were employed and $95 \%$ held a college degree. The mean age of the subjects' children was 6.4 , and $60 \%$ of the children were male and $40 \%$ female. 
Table 2

Subject Characteristics

Parent Characteristics

Child Characteristics

\begin{tabular}{|l|l|l|l|l|l|l|}
\hline & $\begin{array}{l}\text { Number } \\
\text { of subj. }\end{array}$ & $\begin{array}{l}\text { Percent } \\
\text { emplyd }\end{array}$ & $\begin{array}{l}\text { Percent } \\
\text { degreed }\end{array}$ & $\begin{array}{l}\text { Child's } \\
\text { mean age }\end{array}$ & $\begin{array}{l}\text { Percent } \\
\text { of males }\end{array}$ & $\begin{array}{l}\text { Percent } \\
\text { of female }\end{array}$ \\
\hline Asian Ind. Fathers & 20 & $100 \%$ & $90 \%$ & 6.4 & $60 \%$ & $40 \%$ \\
\hline Asian Ind. Mothers & 20 & $70 \%$ & $95 \%$ & 6.4 & $60 \%$ & $40 \%$ \\
\hline First Gen. Fathers & 17 & $100 \%$ & $100 \%$ & 6.4 & $59 \%$ & $41 \%$ \\
\hline First Gen. Mothers & 17 & $53 \%$ & $94 \%$ & 6.4 & $59 \%$ & $41 \%$ \\
\hline Sec. Gen. Fathers & 11 & $100 \%$ & $100 \%$ & 6.5 & $64 \%$ & $36 \%$ \\
\hline Sec. Gen. Mothers & 11 & $64 \%$ & $100 \%$ & 6.5 & $64 \%$ & $36 \%$ \\
\hline Euro-Amr. Fathers & 20 & $100 \%$ & $95 \%$ & 6.7 & $40 \%$ & $60 \%$ \\
\hline Euro-Amr. Mothers & 20 & $65 \%$ & $80 \%$ & 6.7 & $40 \%$ & $60 \%$ \\
\hline
\end{tabular}

Asian Indian Immigrants in the United States

Asian Indian immigrants in the United States, were selected through contacts with various Asian Indian organizations and associations in the Northem California Bay Area and the Los Angeles Area. These metropolitan areas were selected because of their diverse and plentiful Asian Indian populations.

There were 17 father subjects in the first generation group: all were employed and all held college degrees. Among the 17 mother subjects in this group, 53\% were employed and $94 \%$ held college degrees. The mean age of the subjects' children was 6.4 , and $59 \%$ of the children were male and $41 \%$ female.

\section{Second Generation Asian Indians in the United States}

The second generation Asian Indians were selected through the same contacts as the first generation Asian Indians. This group was comprised of eleven couples. Six couples were of interethnic marriages (i.e., an Asian Indian with a non-Asian Indian). 
Therefore, six of the respondents in this group were of other than Asian Indian heritage; specifically, four were Euro-American, one was African American, and one was Pakistani. Five of the second generation couples were in same heritage group marriages; thus, both spouses were Asian Indian. There were 11 father subjects in this group; all were employed and had earned a college degree. Of the 11 mother subjects in this group, $64 \%$ of them were employed and $100 \%$ held a college degree. The mean age of the subjects' children was 6.5 , and $64 \%$ of the children were male and $36 \%$ female.

\section{Euro-Americans}

Euro-Amercian subjects were selected through a few after-school child care centers in the Bay Area. In addition, subjects were found through contacts in the Stanford University area. These neighborhoods are middle to upper middle income areas. There were 20 father subjects in this group, of which $100 \%$ of them were employed and $95 \%$ held a college degree. Among them 20 mother subjects in this group, $65 \%$ were employed and $80 \%$ held a college degree. The mean age of the subjects' children was 6.7 , and $40 \%$ of the children were male and $60 \%$ female.

\section{Instrument}

The questionnaire used in this study was adapted from Block's (1986) Child Rearing Practices Report (CRPR). [See Appendix A for the adapted questionnaire.] Some changes were made in the wording of the items for purposes of clarity for all populations in this study. The questionnaire included 26 statements pertaining to the categories of: parental control, encouragement of independence, emphasis on academic achievement, and nurturance. Agreement with each statement was rated by the subject on a 5-point Likert-type scale where 1 equalled strongly disagree and 5 equalled strongly agree. There were ten additional questions relating to the subject's background: ethnicity, child care arrangements, occupation, years in country of residence, family size, and children's birth order. 
The Block (1986) questionnaire was based on a Q-sort of statements taken from empirical observations of mother-child interactions in various experimental settings. Although the reliability and validity of many self-report measurement tools have been questioned, Block specifically designed this instrument to ensure reliability and validity. Reliabilty was enhanced by: (1) minimizing response sets, such as social desirability, (2) limiting defensiveness in subject response by use of neutral terms, and (3) incorporating flexibility for use in various cultural settings. In order to assess the reliability of the CRPR, Block performed two test-retest studies. In the first test, students in a college psychology course were asked to complete the CRPR at the beginning of the course and then again eight months later at the end of the course. The average item correlation was .71 with a range of .38 to .85 . In the second study, a group of Peace Corps volunteers were asked to complete the report prior to their Peace Corps assignment and then again when they returned, three years later. The average item correlation was .64. Although the tests were not necessarily conducted on parents, this information still represents the test-retest reliability of this particular self-report instrument. The validity of this instrument has been evaluated through the construction of the items. The items were created from observations of 112 mothers interacting with their children in three different settings. Four years after the observations, the mothers were contacted to complete the CRPR. Among the 112 mothers, 76 completed the CRPR. Comparisons between the observed data and the reported data were made using t-tests. Results suggested that the CRPR was a valid self-report form for examining childrearing practices.

\section{Procedures}

Each subject was approached either by the researcher in the United States or by a relative of the researcher in India. The subjects were asked to read and sign a consent form prior to completion of the questionnaire. [See Appendix B for the consent form.] While completing the questionnaire, subjects were instructed to consider their 
interactions with one of their children who was between the ages of five and eight. Each subject was asked to complete a questionnaire independently of his or her spouse and then forward the questionnaire to the researcher through the mail. Each subject completed a confidential questionnaire. The two questionnaires of both mother and father of the same child were kept together for gender comparisons. The importance of considering the interactions of only one child was emphasized since childrearing practices tend to vary for individual children.

Asian Indians in India were approached by an Asian Indian relative of the researcher who lived in Kshatriya Nivas No. 1. Questionnaires were distributed to couples who met the Asian Indian criteria specified previously. The subjects were asked to complete the questionnaires and return them to the researcher's relative. After twenty couples, forty subjects, had completed the questionnaires they were sent back to the United States for data analysis.

First and second generation Asian Indians in the United States were approached by the researcher at various Asian Indian festivals and functions sponsored by Asian Indian associations throughout the Bay Area and the Los Angeles area. In addition many contacts were made through the mail and also via telephone. The subjects were asked to complete the forms and mail them back to the researcher.

Euro-American subjects who met the criteria designated above were approached by the researcher and asked to complete the questionnaire and return it to the researcher through the mail. 


\section{Chapter 4}

\section{RESULTS}

Analyses are presented for each of the four dimensions of childrearing: parental control, encouragement of independence, emphasis on academic achievement and nurturance. A three-way $4 \times 2 \times 2$ analysis of variance (ethnicity, parent gender and child gender) was computed for each question and overall total score. Table 3 presents the mean scores and ANOVA results for the parental control questions.

First, looking at the total score for parental control there were no significant main effects for ethnicity, parental gender, or child gender. However, there were three parental control items which showed significant ethnic differences. Scheffé post hoc comparisons were run to determine which groups differed significantly from each other. As Table 3 shows, Asian Indian (A) and immigrant Asian Indians (I) scored significantly higher than Euro-American (E) subjects on item $\$ 2$ (Physical punishment is best way of disciplining). For question \#14 (I have strict well established rules for child), Asian Indian (A) subjects scored lower than all other groups. In contrast, on question \#22 (When I discipline child, helps him improve), Asian Indians (A) had significantly higher scores than all other groups. For two of the items with significant ethnic differences Asian Indians (A) demonstrated more parental control than other groups, whereas, on one item (I have strict well established rules for my child), Asian Indians (A) scored significantly lower than all other groups. Finally, none of the items had either parent or child gender differences. In addition, none of the interactions were significant. 
Table 3

Mean Scores and ANOVA Results for Ethnicity and Gender for Parental Control

\begin{tabular}{|c|c|c|c|c|c|c|c|}
\hline & \multicolumn{4}{|c|}{ Mean Scores } & \multicolumn{3}{|c|}{ ANOVA Results } \\
\hline Question & $\begin{array}{l}\text { Asian } \\
\text { Indian }\end{array}$ & $\begin{array}{l}\text { Immg } \\
\text { Indian }\end{array}$ & $\begin{array}{l}\text { 2nd } \\
\text { Gen. }\end{array}$ & $\begin{array}{l}\text { Euro } \\
\text { Amer. }\end{array}$ & $\begin{array}{l}\text { Ethn. } \\
\text { F-test }\end{array}$ & $\begin{array}{l}\text { Scheffé } \\
\text { Ethn. } \\
\text { Group } \\
\text { Diff. }\end{array}$ & $\begin{array}{l}\text { Gend. } \\
\text { Diff. }\end{array}$ \\
\hline $\begin{array}{l}\text { \#2. Physical } \\
\text { punishment is best way } \\
\text { of disciplining. }\end{array}$ & 1.80 & 1.85 & 1.63 & 1.30 & $\begin{array}{l}3.7 \\
* * *\end{array}$ & $\begin{array}{l}A>E \\
I>E\end{array}$ & NS \\
\hline $\begin{array}{l}\# 4 . \text { Respect child's } \\
\text { opinions, encourage him } \\
\text { to express them. }\end{array}$ & 4.45 & 4.27 & 4.44 & 4.48 & NS & $\varnothing$ & NS \\
\hline $\begin{array}{l}\text { \#9. Usually take into } \\
\text { account child's } \\
\text { preferences in making } \\
\text { plans for family. }\end{array}$ & 3.88 & 4.06 & 3.88 & 3.90 & NS & $\varnothing$ & NS \\
\hline $\begin{array}{l}\# 11 \text {. I do not allow my } \\
\text { child to get angry with } \\
\text { me. }\end{array}$ & 2.68 & 2.35 & 2.38 & 2.08 & NS & $\varnothing$ & NS \\
\hline $\begin{array}{l}\text { \#14. I have strict, well- } \\
\text { established rules for } \\
\text { child. }\end{array}$ & 2.48 & 3.38 & 3.50 & 3.58 & $\underset{* * *}{9.5}$ & $\begin{array}{l}\mathrm{A}<\mathrm{I} \\
\mathrm{A}<2 \\
\mathrm{~A}<\mathrm{E}\end{array}$ & NS \\
\hline $\begin{array}{l}\text { \#19. When I am angry } \\
\text { with child, I let her } \\
\text { know by expressing } \\
\text { anger verbally. }\end{array}$ & 4.23 & 4.15 & 4.19 & 4.18 & NS & $\emptyset$ & NS \\
\hline $\begin{array}{l}\text { \#22. When I discipline } \\
\text { child, helps him } \\
\text { improve. }\end{array}$ & 4.25 & 3.85 & 3.75 & 3.85 & $\stackrel{2.9}{*}$ & $\begin{array}{l}A>I \\
A>2 \\
A>E\end{array}$ & NS \\
\hline $\begin{array}{l}\text { \#23. Do not allow child } \\
\text { to question my } \\
\text { decisions. }\end{array}$ & 2.58 & 2.24 & 2.13 & 2.13 & NS & $\varnothing$ & NS \\
\hline $\begin{array}{l}\text { \#24. Try to keep child } \\
\text { away from children/ } \\
\text { families w/ ideas/values } \\
\text { different from our own. }\end{array}$ & 2.38 & 2.88 & 2.06 & 2.33 & NS & $\varnothing$ & NS \\
\hline $\begin{array}{l}\text { \#25. Always make sure } \\
\text { that I know where child } \\
\text { is, what she is doing. }\end{array}$ & 4.15 & 4.50 & 4.06 & 4.18 & NS & $\varnothing$ & NS \\
\hline Total Score & 33.85 & 35.53 & 35.00 & 35.47 & NS & $\varnothing$ & NS \\
\hline
\end{tabular}

1 Includes both parent gender and child gender, with each factor analyzed separately.

NS $=$ No Significance, ${ }^{*}=p<0.05,{ }^{* *}=p<0.01,{ }^{* * *}=p<0.001$ 
The next analysis examined the encouragement of independence items. Table 4 presents the mean scores and ANOVA results for the encouragement of independence items. In considering the total score for encouragement of independence, there were no significant main effects for ethnicity, parental gender or child gender. Three items in this category showed significant main effects for ethnicity. As shown in Table 4, Asian Indians (A) and immigrant Asian Indians (I) both scored significantly lower than EuroAmericans (E) on item \#12 (I let my child make decisions for himself or herself). Moreover, on item \#18 (I believe children should not have secrets from their parents), Asian Indians (A), immigrant Asian Indians (I) and second generation Asian Indians (2) all scored significantly higher than Euro-Americans (E). Although item \#16 (I give my child a good many duties and family responsibilities) showed a significant main effect for ethnicity, Scheffé analyses indicated that no two groups differed significantly from each other. There were no significant differences related to gender of parent or child. In addition, no interactions were significant. 
Table 4

Mean Scores and ANOVA Results for Ethnicity and Gender for Encouragement of Independence

\begin{tabular}{|l|c|c|c|c||c|c|c|}
\hline \multicolumn{1}{|c|}{ Question } & \multicolumn{3}{|c|}{ Mean Scores } & \multicolumn{3}{|c|}{ ANOVA Results } \\
\hline Indian & Immg & Indian & $\begin{array}{c}\text { 2nd } \\
\text { Gen. }\end{array}$ & $\begin{array}{c}\text { Euro } \\
\text { Amer. }\end{array}$ & $\begin{array}{c}\text { Ethn. } \\
\text { F-test }\end{array}$ & $\begin{array}{c}\text { Scheffé } \\
\text { Ethn. } \\
\text { Group } \\
\text { Diff. }\end{array}$ & $\begin{array}{c}\text { Gend. } \\
\text { Diff. }\end{array}$ \\
\hline $\begin{array}{l}\text { \#6. If my child gets into } \\
\text { a conflict with another } \\
\text { child, I expect him or } \\
\text { her to handle the } \\
\text { problem mostly by } \\
\text { himself or herself. }\end{array}$ & 3.90 & 3.53 & 3.56 & 3.80 & NS & $\varnothing$ & NS \\
\hline $\begin{array}{l}\text { \#12. I let my child } \\
\text { make decisions for } \\
\text { himself or herself. }\end{array}$ & 3.55 & 3.21 & 3.81 & 4.05 & 6.4 & $\begin{array}{c}\text { A<E } \\
\text { I<E }\end{array}$ & NS \\
\hline $\begin{array}{l}\text { \#16. I give my child a } \\
\text { good many duties and } \\
\text { family responsibilities. }\end{array}$ & 2.88 & 3.09 & 3.06 & 3.48 & 2.8 & $\varnothing$ & NS \\
\hline $\begin{array}{l}\text { \#18. I believe children } \\
\text { should not have secrets } \\
\text { from their parents. }\end{array}$ & 3.88 & 4.12 & 3.69 & 2.58 & 13.8 & $\begin{array}{c}\text { A>E } \\
\text { I }>\text { E } \\
\text { 2 }\end{array}$ & NS \\
\hline $\begin{array}{l}\text { \#20. I teach my child } \\
\text { that he or she is } \\
\text { responsible for what } \\
\text { happens to him or her. }\end{array}$ & 3.63 & 3.82 & 3.75 & 4.10 & NS & $\varnothing$ & NS \\
\hline $\begin{array}{l}\text { \#21. I encourage my } \\
\text { child to be independent } \\
\text { of me. }\end{array}$ & 3.70 & 3.68 & 3.94 & 4.00 & NS & $\varnothing$ & NS \\
\hline \multicolumn{1}{|l}{ Total Score } & 21.52 & 21.44 & 21.81 & 22 & NS & $\varnothing$ & NS \\
\hline
\end{tabular}

1 Includes both parent gender and child gender, with each factor analyzed separately.

$\mathrm{NSS}=$ No Significance, ${ }^{*}=\mathrm{p}<0.05,{ }^{* *}=\mathrm{p}<0.01,{ }^{* * *}=\mathrm{p}<0.001$ 
Turning to the analysis for emphasis on achievement, Table 5 depicts the mean scores and ANOVA results for the achievement items. As Table 5 demonstrates, there was a significant difference on the total score for emphasis on academic achievement. According to the Scheffé analyses, immigrant Asian Indians (I) scored significantly higher than Euro-Americans (E). Five of the six items in the achievement category showed significant differences for ethnicity. Euro-Americans (E) scored significantly lower than immigrant Asian Indians (I) and second generation Asian Indians (2) on item \#1 (I insist that my child always do his or her best). On item \#8 (I always expect my child to respect his or her teacher), Euro-Americans (E) scored significantly lower than Asian Indians (A) and immigrant Asian Indians (I). In addition, all three Asian Indian (A, I, 2) groups scored significantly higher than Euro-Americans (E) on item \#10 (I think a child should be encouraged to achieve at a higher level than other children). On item \#13 (I feel that it is good for a child to compete with other children in academic settings), immigrant Asian Indians (I) scored significantly higher than Euro-Americans (E). Asian Indians (A) scored significantly higher than both second generation Asian Indians (2) and Euro-Americans (E) on item \#17 (I expect my child to impress others with his or her performance). There were no significant main effects for parent or child gender, nor were there any significant interactions. 
Table 5

Mean Scores and ANOVA Results for Ethnicity and Gender for Emphasis on Achievement

\begin{tabular}{|c|c|c|c|c|c|c|c|}
\hline & \multicolumn{4}{|c|}{ Mean Scores } & \multicolumn{3}{|c|}{ ANOVA Results } \\
\hline Question & $\begin{array}{l}\text { Asian } \\
\text { Indian }\end{array}$ & $\begin{array}{l}\text { Immg } \\
\text { Indian }\end{array}$ & $\begin{array}{l}\text { 2nd } \\
\text { Gen. }\end{array}$ & $\begin{array}{l}\text { Euro } \\
\text { Amer. }\end{array}$ & $\begin{array}{l}\text { Ethn. } \\
\text { F-test }\end{array}$ & $\begin{array}{l}\text { Scheffé } \\
\text { Ethn. } \\
\text { Group } \\
\text { Diff. }\end{array}$ & $\begin{array}{c}1 \\
\text { Gend. } \\
\text { Diff. }\end{array}$ \\
\hline $\begin{array}{l}\text { \#1. I insist that my } \\
\text { child always do his or } \\
\text { her best. }\end{array}$ & 3.90 & 4.47 & 4.13 & 3.33 & $\begin{array}{l}9.6 \\
* * *\end{array}$ & $\begin{array}{l}I>E \\
2>E\end{array}$ & NS \\
\hline $\begin{array}{l}\text { \#7. I demand a great } \\
\text { deal from my child in } \\
\text { his or her school work. }\end{array}$ & 3.53 & 4.03 & 3.88 & 3.53 & NS & $\varnothing$ & NS \\
\hline $\begin{array}{l}\text { \#8. I always expect my } \\
\text { child to respect his or } \\
\text { her teacher. }\end{array}$ & 4.70 & 4.62 & 4.44 & 4.23 & $\begin{array}{l}5.1 \\
* * \\
\end{array}$ & $\begin{array}{l}A>E \\
I>E\end{array}$ & NS \\
\hline $\begin{array}{l}\text { \#10. I think a child } \\
\text { should be encouraged to } \\
\text { achieve at a higher level } \\
\text { than other children. }\end{array}$ & 4.10 & 3.85 & 3.88 & 2.85 & $\frac{11.3}{* * *}$ & $\begin{array}{l}\mathrm{A}>\mathrm{E} \\
\mathrm{I}>\mathrm{E} \\
2>\mathrm{E}\end{array}$ & NS \\
\hline $\begin{array}{l}\text { \#13. I feel that it is } \\
\text { good for a child to } \\
\text { compete with other } \\
\text { children in academic } \\
\text { settings. }\end{array}$ & 4.00 & 4.21 & 3.69 & 3.40 & $\begin{array}{l}4.3 \\
* *\end{array}$ & $\mathrm{I}>\mathrm{E}$ & NS \\
\hline $\begin{array}{l}\text { \#17. I expect my child } \\
\text { to impress others with } \\
\text { his or her academic } \\
\text { performance. }\end{array}$ & 3.38 & 2.79 & 2.31 & 2.28 & $\begin{array}{l}6.9 \\
* * * *\end{array}$ & $\begin{array}{l}A>2 \\
A>E\end{array}$ & NS \\
\hline Total Score & 24.6 & 25.97 & 25.31 & 23.6 & $2.83 *$ & $\mathrm{I}>\mathrm{E}$ & NS \\
\hline
\end{tabular}

1 Includes both parent gender and child gender, with each factor analyzed separately.

NS $=$ No Significance, ${ }^{*}=p<0.05,{ }^{* *}=p<0.01,{ }^{* * *}=p<0.001$

The last analysis examined the items for nurturance. Table 6 depicts the mean scores and ANOVA results for nurturance items. Looking at total scores, there was a significant main effect for ethnicity. Scheffé results showed that Euro-Americans (E) scored significantly higher than Asian Indians (A) and immigrant Asian Indians (I). In 
addition, Asian Indians (A) scored significantly lower than Euro-Americans (E) on item \#5 (I express affection by hugging, kissing, and holding my child) and item \#15 (My child and I have warm, intimate times together). However, Asian Indians (A) scored significantly higher than all three groups and immigrant Asian Indians (I) scored significantly higher than Euro-Americans (E) on item \#26 (I believe that too much affection and tenderness can harm or weaken a child).

This was the only scale on which there were significant differences for parent gender. Looking at the total score, fathers $(M=17.98)$ scored lower overall than mothers $(M=18.66$ ) on nurturance items. On item \#3 (I am usually affectionate with my child), mothers $(M=4.46)$ scored signficantly higher than fathers $(M=4.32)$. Similarly, on item \#5 (Express affection by hugging, kissing and holding my child), mothers $(M=4.67)$ outscored fathers $(M=4.37)$. Further, fathers $(M=4.24)$ were less likely to have warm, intimate times with child as described in item \#15 than mothers $(M=4.49)$. 
Table 6

Mean Scores and ANOVA Results for Ethnicity and Gender for Nurturance

\begin{tabular}{|c|c|c|c|c|c|c|c|}
\hline & \multicolumn{4}{|c|}{ Mean Scores } & \multicolumn{3}{|c|}{ ANOVA Results } \\
\hline Question & $\begin{array}{l}\text { Asian } \\
\text { Indian }\end{array}$ & $\begin{array}{l}\text { Immg } \\
\text { Indian }\end{array}$ & $\begin{array}{l}\text { 2nd } \\
\text { Gen. }\end{array}$ & $\begin{array}{c}\text { Euro } \\
\text { Amer. }\end{array}$ & $\begin{array}{l}\text { Ethn. } \\
\text { F-test }\end{array}$ & $\begin{array}{l}\text { Scheffé } \\
\text { Ethn. } \\
\text { Group } \\
\text { Diff. }\end{array}$ & $\begin{array}{r}1 \\
\text { Gend. } \\
\text { Diff. }\end{array}$ \\
\hline $\begin{array}{l}\text { \#3. I am usually very } \\
\text { affectionate with my } \\
\text { child. }\end{array}$ & 4.38 & 4.38 & 4.32 & 4.45 & NS & $\varnothing$ & $\begin{array}{c}\text { PG } \\
3.9 \\
* \\
\end{array}$ \\
\hline $\begin{array}{l}\text { \#5. I express affection } \\
\text { by hugging, kissing and } \\
\text { holding my child. }\end{array}$ & 4.28 & 4.62 & 4.50 & 4.68 & $\underset{*}{2.9}$ & $\mathrm{~A}<\mathrm{E}$ & $\begin{array}{l}\mathrm{PG} \\
7.1 \\
* *\end{array}$ \\
\hline $\begin{array}{l}\text { \#15. My child and I } \\
\text { have warm, intimate } \\
\text { times together. }\end{array}$ & 4.13 & 4.50 & 4.32 & 4.53 & 3.2 & $\mathrm{~A}<\mathrm{E}$ & $\begin{array}{l}\text { PG } \\
4.2 \\
*\end{array}$ \\
\hline $\begin{array}{l}\$ 26 . \text { I believe that too } \\
\text { much affection and } \\
\text { tenderness can harm or } \\
\text { weaken a child. }\end{array}$ & 3.90 & 2.47 & 2.09 & 1.65 & $\underset{* * *}{22.1}$ & $\begin{array}{l}A>I \\
A>2 \\
A>E \\
I>E\end{array}$ & NS \\
\hline Total Scores & 17.67 & 17.97 & 18.31 & 19.3 & $\begin{array}{l}7.72 \\
* * * *\end{array}$ & $\begin{array}{l}\mathrm{A}<\mathrm{E} \\
\mathrm{I}<\mathrm{E}\end{array}$ & $\begin{array}{l}\mathrm{PG} \\
4.4 \\
*\end{array}$ \\
\hline
\end{tabular}

1 Includes both parent gender and child gender, with each factor analyzed separately.

NS $=$ No Significance, ${ }^{*}=p<0.05,{ }^{* *}=p<0.01,{ }^{* * *}=p<0.001$ 


\section{Chapter 5}

\section{DISCUSSION}

The findings of this study show some interesting cultural differences and similarities in childrearing practices among Asian Indians, first generation immigrant Asian Indians, second generation immigrant Asian Indians, and Euro-Americans as well as between mothers and fathers. A more detailed discussion regarding the results for each dimension will follow.

In examining the total score for parental control, there were no ethnic group differences, although there were significant differences in a few items. All groups tended to disagree with the use of physical punishment, Asian Indian and Asian Indian immigrants were more likely than Euro-Americans to agree that it is a good discipline tool. In addition, Asian Indians scored significantly higher than all other groups in the belief that children improve from discipline. These findings support the literature which suggests that Asian families find punishment to be an effective form of discipline and discipline to be a means to help children improve (Chao, 1983). Only one other item ( I have strict, well-established rules for my child) produced significant ethnic group differences, with Asian Indians scoring lower than all other groups.

While there were few ethnic background variations, there were some interesting patterns of differences and similarities. In method of discipline (physical punishment), the Asian Indian and immigrant groups were very similar and, as a group, quite distinct from the Euro-American parents. This pattern suggests that first generation immigrants are holding on to their native values. The second generation parents scored between the native/first generation and Euro-American parents. This pattern shows a clear acculturation effect for the second generation group. Similarly, while Asian Indians scored the lowest in having strict rules, the scores of second generation and EuroAmerican parents were quite similar. In between, but closer to the other two American 
groups, were the immigrant parents. Immigrant parents may come to see that they must establish rules for their children because the cultural expectations for child behavior in India do not exist in the United States. Similarly, because of their changing value system of rearing children in a more permissive culture, they may feel that discipline may not be as effective in improving their child's behavior as it might have been in India. This explanation may indicate why immigrant parents have a higher, though not significantly higher, agreement that they try to keep their children away from families or children with different values and that they always know what their child is doing. In the same vein, immigrant parents are least likely, though not significantly so, to respect their child's opinions. Immigrant parents often express the most frustration in parenting when their cultural values clash with those of the host culture (Banks \& Banks, 1995). The pattern of results here are consistent with this body of literature. These results may suggest that there is indeed an effect of acculturation, which also supports the literature (Caudill \& Frost, 1973; Lin \& Fu, 1991; Madanipour, 1977).

The results described here show some consistency with the results found by Lin and Fu (1991) who found Chinese parents to be more controlling than immigrant Chinese parents who were more controlling than Caucasian Americans. Similar to the present study, Lin and Fu did not find parent gender differences in the category of parental control. Additionally, there were no significant differences in parents' attitudes according to their child's gender.

There were no significant ethnic group differences for the total score in the category of encouragement of independence. In fact, there were only significant ethnic differences in three items. The analysis on item \#12 (I let my child make decisions for himself) resulted in a significant difference with Euro-Americans scoring higher than all other groups. This result is consistent with the literature which suggests that EuroAmericans promote decision making in their children (Feldman \& Rosenthal, 1991). In 
addition, immigrant Asian Indians had the lowest mean score. This may be due to the fear that immigrants have in acclimating to a new culture and the need to be more involved in decisions for their children. The mean score for the second generation group was very close to the Euro-American mean score, which may reflect acculturation and less fear about what is no longer a new culture.

Results for item \#16 which focused on giving children family responsibilities were significant. Euro-Americans scored higher than all other groups and Asian Indians scored the lowest. Both immigrant Asian Indian and second generation Asian Indian groups scored right in the middle. This result is consistent with previous literature which shows that Asian Indians allow children much time for studying and dismissed them from household duties (Saran, 1985).

A significant difference was also found in item \#18 (I believe children should not have secrets from their parents). Euro-Americans scored significantly lower than all other groups. This is again consistent with the literature that suggests that EuroAmerican parents give their children more autonomy than Asian parents (Feldman \& Rosenthal, 1991). Asian Indian immigrants scored higher than all other groups in this item.

These results only partially support the hypothesis that Asian Indians would show less encouragement of independence than Euro-Americans since only two items produced significant ethnic group differences. Some acculturation effects on second generation immigrants were found in this category. There was a lack of acculturation effects on immigrant parents which may be due to fear of a new culture where children are exposed to new values that differ from the ones instilled in the parents.

Lin and Fu (1991) found that Chinese and Chinese immigrants showed more evidence of encouragement of independence than did Caucasian parents which is contrary to the literature. The present study did find that overall Euro-Americans encouraged 
independence more than the other groups. Therefore, these results are not consistent with those of Lin and Fu (1991). Similar to Lin and Fu, though, attitudes did not vary according to parent gender and child gender.

There was a significant group difference for total scores in emphasis on academic achievement. Immigrant Asian Indians scored significantly higher than Euro-Americans. It is surprising that Asian Indians did not score the highest. However, these results may reflect different cultural assumptions regarding achievement, where Asian Indian parents do not feel that they must use a childrearing practice to emphasize achievement it is simply the way of life. Furthermore, immigrant Asian Indian parents may put an even higher emphasis on academics in the United States because they feel that academic standards are too lax.

Items \#1 $($ insist my child always do her best), \#10 (A child should be encouraged to achieve at a higher level than other children), \#13 (It is good for a child to compete with other children in academic settings), and \#17 (I expect my child to impress others with his performance) all reflect a parent's desire to see their child perform well and to excel over others. In each of these items, Euro-American parents scored significantly lower than at least one Asian Indian group. For item \#1, both immigrant Asian Indian groups scored higher than Euro-Americans. However, Asian Indians did not score significantly higher. Asian Indian parents may feel that they do not have to insist their children do their best because it is assumed that they will do their best. On item \#10, all Asian Indians groups scored significantly higher than Euro-Americans. There seems to be some evidence that parents of Asian Indian decent feel their children should achieve at higher levels than their peers. In India status is often measured by academic success which is often a precursor for achievement in life: career, social status, and eligibility for marriage (Saran, 1985). 
Overall, in the area of academic achievement the results of the present study support the literature. However, there was some evidence that Asian Indians did not always score higher than immigrant Asian Indians. Cultural values must be considered in this scenario since values regarding achievement in India may be assumed, whereas they may need to be enforced with immigrant children because of the differing value system. This data also supports Lin and Fu's (1991) results which state that immigrant Chinese parents continue to follow Confucian principles of high expectations for achievement.

The results for the category of nurturance will be described now. For the item \#5 (I express affection by hugging, kissing, and holding my child) and item \#15 (My child and I have warm, intimate times together), results showed that Asian Indians scored significantly lower than Euro-Americans. This finding is consistent with the literature that suggests Asians do not show much affection to their children (Chao, 1983). There was a highly significant difference for ethnicity on the item describing that too much affection can weaken a child. Asian Indians scored higher than all other groups on this item and first generation immigrant Asian Indians scored higher than Euro-Americans. This finding is consistent with the literature by Bond and Wang (1983) which suggests that Asian families may be reluctant to show affection because too much affection can weaken family bonds.

There were also significant differences for parent gender for three items regarding displaying affection and having warm, intimate times with children. In all of these items, mothers scored higher than fathers. This finding is consistent with the literature which suggests that mothers are more nurturing than fathers (Kotelchuck, 1972; Maccoby \& Martin, 1983). Moreover, Roopnarine et al. (1990) and Kakar (1978) described Asian Indian fathers as considerably less nurturing than mothers. In addition, they described mothers as rather indulgent with their children. In contrast to these findings, Lin and Fu's 
(1991) study did not show any difference, ethnic or gender (parent or child), for the category of nurturance.

Overall, the results in this study show that there is some degree of generational change in these specific areas of childrearing. There was also evidence of acculturation, especially in parental control and academic achievement. There was little evidence of gender differences for either parents or children except in the area of nurturance. The lack of gender differences may reflect the child's age group considered in this study (ages $5-8)$; this may be an age range where children are treated similarly by both parents, and gender differences become more prominent in either younger or older ages. In addition, there may be some degree of reporting bias in the data.

Cultural differences and similarities in childrearing attitudes is clearly an area requiring further investigative attention. One limitation of the current study is that the same questionnaire was used for each sample, leaving much to the individual subject's interpretation. Since language barriers can affect results, in future, a more clear definition of each item of the questionnaire should be controlled. In addition, individual values also affect results of questionnaire. Possibly the incorporation of background information based on values for the the areas of study could be useful. Further, research is essential in the field of child development in order to enhance our knowledge of parental expectations and standards of immigrant families of all backgrounds. 


\section{REFERENCES}

Ainsworth, M. D. S., \& Bell, S. M. (1969). Some contemporary patterns of mother-infant interaction in the feeding situation. In A. Ambrose (Ed.), Stimulation in early infancy. New York: Academic Press.

Ainsworth, M. D. S., Bell, S. M., \& Stayton, D. J. (1971). Individual differences in strange situation behavior of one-year-olds. In H. R. Schaffer (Ed.), The origins of human social relations (pp. 49-67). London: Academic Press.

Alwin, D. F. (1988). From obedience to autonomy: Changes in traits desired in children, 1924-1978. Public Opinion Quarterly, 52, 33-52.

Baldwin, A. L. (1948). Socialization and the parent-child relationship. Child Development, $\underline{19}(3), 127-136$.

Banks, J. A., \& Banks, C. A. (1996). Handbook of research on multicultural education. New York: MacMillan.

Baumrind, D. (1967). Child care practices anteceding three patterns of preschool behavior. Genetic Psychology Monographs, 75, 43-88.

Baumrind, D. (1971). Current patterns of parental authority. Developmental Psychology Monographs, 4, 1-102. 
Baumrind, D. (1973). The developmental instrumental competence through socialization. In A. D. Pick (Ed.), Minnesota Symposium on Child Psychology (Vol. 7, pp. 17-68). Minneapolis, MN: University of Minnesota Press.

Baumrind, D. (1977, March). Socialization determinants of personal agency. Paper presented at the meeting of the Society for Research in Child Development, New Orieans, LA.

Baumrind, D. (1979). Sex-related socialization effects. Paper presented at the meetings of the Society for Research in Child Development, San Francisco, CA.

Baumrind, D., \& Black, A. E. (1967). Socialization practices associated with dimensions of competence in preschool boys and girls. Child Development, 38, 291-327.

Berry, J. W. (1980). Acculturation as varieties of adaptation. In A. M. Padilla, (Ed.), Acculturation: Theory, models and some new findings (pp. 9-25). Boulder, CO: Westview.

Block, J. (1986). The child-rearing practices report (CRPR): A set of $Q$ items for the description of parental socialization attitudes and values. Berkeley, CA: University of California.

Block, J. H. (1971). Lives through time. Berkeley, CA: Bancroft Books. 
Bond, M. H., \& Wang, S. (1983). China: Agressive behavior and the problems of maintaining order and harmony. In A. P. Goldstein \& M. H. Segall (Eds.), Aggression in global perspective (pp. 58-74). New York: Pergamon.

Bronfenbrenner, U. (1979). The ecology of human developement: Experiments by nature and design (pp. 16-43). Cambridge, MA: Harvard University.

Caudill, W. A., \& Frost, L. A. (1973) A comparison of maternal care and infant behavior in Japanese-American, American, and Japanese families. In W.P. Lebra (Ed.), Youth, socialization, and mental health: Volume III of mental health research in Asia and the pacific (pp. 16-43). Honolulu, HI: The Universtiy Press of Hawaii.

Chao, P. (1983). Chinese kinship. London: Kegan Paul International.

Chen, C., \& Uttal, D. H. (1988). Cultural values, parents' beliefs, and children's achievement in the United States and China. Human Development 31, 351-358.

Clarke-Stewart, A. K. (1973). Interactions between mothers and their young children: Characteristics and consequences. Monographs of the Society for Research in Child Development, 38 , (6 and 7).

Coopersmith, S. (1967). The antecedents of self-esteem. San Francisco, CA: W. H. Freeman.

Damon, W. (1983). Social and personality development New York: W. W. Norton. 
Dasgupta, S. S. (1989). Qn the trail of an uncertain dream: Indian immigrant experiences in America New York: AMS.

Dornbusch, S. M., Ritter, P. L., Leiderman, P. H., Roberts, D. F., \& Fraleigh, M. J. (1987). The relation of parenting style to adolescent school performance. Child Development, 58, 1244-1257.

Edwards, C. P., \& Whiting, B. B. (1977). Sex differences in children's social interaction. Unpublished report to the Ford Foundation.

Engel, J. W. (1984). Marriage in the People's Republic of China: Analysis of the new law. Journal of Marriage and the Family, 46, 947-954.

Feldman, S. S., \& Rosenthal, D. A. (1990). The accultaration of autonomy expectations in Chinese high schoolers residing in two western nations. International Journal of Psychology, 25(3), 259-281.

Feshbach, N. D. (1977). The relationship of child-rearing factors to children's aggression, empathy, and related positive and negative behaviors. In J. de Wit, \& W. W. Hartup (Eds.), Determinants and origins of aggressive behavior (pp. 115-156). The Hague: Mouton Press.

Ghaffarian, S. (1987). The acculturation of Iranians in the United States. Joumal of Social Psychology 127(6), 565-571. 
Graham, S. (1992). Atributional and emotional determinants of aggression among African-American and Latino young adolescents. Developmental Psychology, 28(4), $731-740$.

Grichting, W. (1970). The value system in Taiwan, 1970. Taipei, Taiwan.

Grolnick, W. S., \& Ryan, R. M. (1989). Parent styles associated with children's self-regulation and competence in school. Journal of Educational Psychology, 81(2), 143-154.

Hale-Benson, J. (1982). Black children: Their roots, culture, and learning styles. Baltimore, MD: Johns Hopkins University Press.

Helwig, A. W., \& Helwig, U. M. (1980). An immigrant success story: East Indians in America. Philidelphia, PA: University of Pennsylvania Press.

Ho, D. Y. F. (1981). Traditional patterns of socialization in Chinese society. Acta Psychologica Taiwanica, 23, 81-95.

Hoffman, M. L. (1970). Moral development. In P. H. Mussen (Ed.), Carmichael's Manual of Child Psychology (3rd ed., Vol. 2, pp. 261-359). New York: Wiley.

Hsu, F. L. K. (1981). Americans and Chinese: Passages to differences. Honolulu, HI: University Press of Hawaii. 
Huang, L. N., \& Ying, Y. W. (1989). Chinese American children and adolescents. In J. T. Gibbs, L. N. Huang \& Associates (Eds.), Children of color: Psychological interventions with minority children (pp. 30-66). San Francisco, CA: Jossey-Bass.

Jung, M. (1984). Structural family therapy: Its application to Chinese families. Family Process, 23, 365-374.

Kakar, S. (1978). The inner-world: A pshycho-analytic study of childhood and society in India New Delhi: Oxford University.

Kishor, N. (1983). Locus of control and academic achievement. Journal of Cross-Cultural Psychology, 14(3), 297-308.

Kotelchuck, M. (1972). The nature of the child's tie to his father to his father. Doctoral dissertation, Harvard University.

Lamb, M. E. (1981). Fathers and child development: An integrative overview. In M. E. Lamb (Ed.), The role of the father in child development (pp. 1-70). New York: Wiley.

Lamborn, S. D., Mounts, N. S., Steinberg, L., \& Dombusch, S. M. (1991). Patterns of competence and adjustment among adolescents from authoritative, authoritarian, indulgent, and neglectful families. Child Deveioputuil i2, in:49-io6s. 
Levine, R. A. (1974). Parental goals: A cross-cultural view. Teachers College Record, $\underline{76}(2), 226-239$.

Levine, R. A. (1988). A cross-cultural perspective on parenting. In M. D. Fantini, \& R. Cardenas (Eds.), Parenting in a multicultural society (pp. 17-26). New York: Longman.

Lin, C. C. \& Fu, V. R. (1990). A comparison of child-rearing practices among Chinese, immigrant Chinese, and Caucasian-American parents. Child Development, $\underline{61}$, 429-433.

Lindholm, K. J. (1981). Communicative socialization: Parent-child and sibling interactions. Doctoral dissertation, University of California, Los Angeles.

Loeb, R. C., Horst, L., \& Horton, P. J. (1980). Family interaction patterns associated with self-esteem in preadolescent girls and boys. Merrill-Palmer Quarterly, 26, 203-217.

Maccoby, E. (1980). Social development: Psychological growth and the parentchild relationship. New York: Harcourt Brace Jovanovich.

Maccoby, E. E, \& Martin, J. A. (1983). Socialization in the context of the family: Parent-child interaction. In E.M. Hetherington (Ed.), Handbook of Child Psychology: Vol.4. Socialization, Personality, and Social Development (4th ed., pp. 1102). New York: Wiley. 
Madanipour, M. S. (1977). Mother-child interactions as a function of acculturation: A comparitive analysis of Iranians residing in Iran and the United States. Doctoral dissertation, University of California, Los Angeles.

Martinez, E. A. (1993). Parenting young children in Mexican American/Chicano families. In H. P. McAdoo (Ed), Family ethnicity: Strenth in diversity (pp. 184-195), Sage: Newbury Park.

Mena, F. J., Padilla, A. M., \& Maldonado, M. (1987). Acculturative stress and specific coping strategies among immigrant and later generation college students. Hispanic Journal of Behavioral Sciences, 9, 207-225.

Ogbu, J. U. (1985). Cultural ecological influences on minority education. Language Arts, 62(8), 860-869.

Olweus, D. (1980). Familial and tempermental determinants of aggressive behavior in adolescent boys: A causal analysis. Developmental Psychology, 16, 644660.

Padilla, A. M. (1980). The role of cultural awareness and ethnic loyalty in acculturation. In A. M. Padilla (Ed.), Acculturation: Theory models and some new findings (pp. 47-84). Boulder, CO: Westview.

Padilla, A. M., \& Lindholm, K. J. (1992, August). What do we know about culturally diverse children? Paper presented at the American Psychological Association annual meeting, Washington, D.C. 
Padilla, A. M. \& Lindholm, K. J. (1995). Quantitative educational research with ethnic minorities. In J. A. Banks, \& C. A. Banks (Eds.), Handbook of Research on Multicultural Education (pp. 97-113). New York: MacMillan.

Patel, N., Power, T. G., \& Bhavnagri, N. P. (1996). Socialization values and practices of Indian immigrant parents: Correlates of modernity and acculturation. Child Development, 67, 302-313.

Patterson, G. R. (1976). The aggressive child: Victim and architect or a coercive system. In L. A. Hamerlynck, L. C. Handy, \& E. J. Mash (Eds.), Behavior modification and families: I. theory and research (pp. 147-204). New York: Academic Press.

Rajagopalachari, C. (1973). Ramayana. Baratiya Vidya Bhavan: Bombay.

Ramirez, O. (1989). Mexican American children and adolescents. In J. T. Gibbs, L. N. Huang \& Associates (Eds.) Children of color: Psychological interventions with minority children (pp. 224-250). San Francisco, CA: Jossey-Bass.

Ramu, G. (1977). Family and caste in urban India: A case study. New Delhi: Vikas.

Roland, A. (1988). In search of self in Indian and Japan. New Jersey: Princeton University. 
Roopnarine, J. L., \& Hossain, Z. (1992). Parent-child interactions in urban Indian families in New Delhi: Are they changing? In J. L. Roopnarine, D. B. Carter \& I. E. Sigel (Eds.), Advances in applied developmental psychology: Vol. 5. Parent-child socialization in diverse cultures (pp. 1-16). Norwood, New Jersey: Ablex.

Roopnarine, J. L., Talukder, E., Jain, D., Joshi, P., \& Srivastav, P. (1990). Characteristics of holding, patterns of play, and social behaviors between parents and infants in New Delhi, India. Developmental Psychology, 26(4), 667-673.

Rosenthal, D. A., \& Feldman, S. S. (1990). The acculturation of Chinese immigrants: Perceived effects of family functioning of length of residence in two cultural contexts. Journal of Genetic Psychology, 151, 495-514.

Salgado de Snyder, V. N., Lopez, C., \& Padilla, A. M. (1982). Ethnic identity and cultural awareness among the offspring of Mexican interethnic marriages. Journal of Early Adolescence, 2, 277-282.

Saltzstein, H. D. (1976). Social influences and moral development: A perspective on the role of parents and peers. In T. Lickona (Ed.), Moral development and behavior (pp. 76-92). New York: Holt, Rinehart, \& Winston.

Santrock, J. W. (1990). Adolescence Dubuque: Brown.

Saran, P. (1985). The Asian Indian experience in the United States. Cambridge, MA: Schenkman. 
Sears, R. R., Maccoby, E. E., \& Levin, H. (1957). Pattems of child rearing. Evanston: Row Peterson.

Segal, U. (1991, April). Cultural variables in Asian Indian families. Families in society: Journal of Contemporary Human Services, 233-242.

Skipper, J. K., \& Noss, G. (1966). Dating behavior: A framework for analysis and an illustration. Journal of Marriage and the Family, 28, 412-420.

Spencer, M. B., \& Dornbusch, S. M. (1990). Challenges in studying minority youth. In S. S. Feldman, \& G. R. Elliot (Eds.), At the threshold: The developing adolescent (pp. 123-146). Cambridge: Harvard University Press.

Steinberg, L., \& Silverberg, S. (1986). The vicissitudes of autonomy in early adolescence. Child Development, 57, 841-885.

Stevenson, H. W., Chen, C., \& Lee, S. (1992). Chinese families. In J. L. Roopnarine, D. B. Carter, \& I. E. Sigel (Eds.), Advances in applied developmental psychology: Vol. 5. Parent-child socialization in diverse cultures (pp. 17-33). Norwood, NJ: Ablex.

Stevenson, H. W., \& Lee, S. (1990). Contexts of achievement: A study of American, Chinese, and Japanese children. Monographs of the Society for Research in Child Development, 55(1-2), 1-123. 
Steward, M., \& Steward, D. (1973). The observation of Anglo, Mexican and Chinese-American mothers teaching their young sons. Child Development, 44, 329-337.

Sussman, M. B. (1953). The help pattern in the in the middle class family. American Sociological Review, 18, 22-28.

Suzuki, B. H. (1980). The Asian-American family. In M. D. Fantini \& R. Cardenas (Eds.), Parenting in a multi-cultural society (pp. 74-102). New York: Longman.

Wakil, S. P., Siddique, C. M., \& Wakil, F. A. (1981). Between two cultures: A study of socialization of children of immigrants. Journal of Marriage and the Family, 43 , 929-940.

Whiting, J. W., \& Child, L (1953). Child training and personality. New Haven: Yale.

Whiting, B. B. \& Whiting, J. W. M. (1973). Altruistic and egoistic behavior in six cultures. In L. Nader \& T. W. Maretzki (Eds.), Cultural illness and health: Essays in human adaptation (pp. 329-364). Washington, D.C.: American Anthropological Association.

Vega, W. A., Hough, R. L., \& Romero, A. (1983). Family life patterns of Mexican-Americans. In G. Johnson Powell (Ed.) The psychosocial development of minority group children (pp. 194-215). New York: Brunner/Mazel. 
Yamamoto, J., \& Kubota, M. (1983). The Japanese-American family. In G. Johnson Powell (Ed), The psychosocial development of minority group children (pp. 237-247). New York: Brunner/Mazel. 


\section{Appendix A}

\section{Childrearing Practices Questionnaire}

Instructions: Please focus on only one of your children between the ages of 5 and 8 .

Age of child: years.

Sex of this child: male female

Grade in school:

Birthorder (i.e. first, second, third, etc.):

Total number of children:

I am the child's: Mother

Father

Please indicate the extent to which the following statements describe your relationship with your child who is between the ages of 5 and 8 . If you strongly agree with the statement, circle 5; If you somewhat agree with the statement, circle 4; If you are uncertain about the statement, circle 3; If you somewhat disagree with the statement, circle 2; If you strongly disagree with the statement, circle 1.

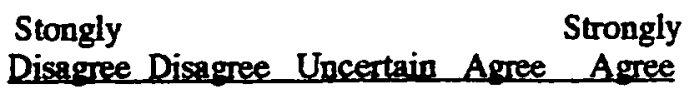

\section{I insist that my child always do his or her best.}

2. I believe physical punishment to be the best way of disciplining.

3. I am usually very affectionate with my child.

4. I respect my child's opinions and encourage $\begin{array}{lllllll}1 & 2 & 3 & 4 & 5\end{array}$ him or her to express them.

5. I express affection by hugging, kissing, and holding my child.

$\begin{array}{llllllll}\text { 6. If my child gets into a conflict with another } & 1 & 2 & 3 & 4 & 5\end{array}$ child, I expect him or her to handle the problem mostly by himself or herself.

7. I demand a great deal from my child in his or her school work.

8. I always expect my child to respect his or her teacher.

9. I usually take into account my child's preferences in making plans for the family.

$\begin{array}{lllll}1 & 2 & 3 & 4 & 5\end{array}$

$\begin{array}{lllll}1 & 2 & 3 & 4 & 5\end{array}$

$\begin{array}{lllll}1 & 2 & 3 & 4 & 5\end{array}$

$\begin{array}{lllll}1 & 2 & 3 & 4 & 5\end{array}$

$\begin{array}{lllll}1 & 2 & 3 & 4 & 5\end{array}$

$\begin{array}{lllll}1 & 2 & 3 & 4 & 5\end{array}$

$\begin{array}{lllll}1 & 2 & 3 & 4 & 5\end{array}$


10. I think a child should be encouraged to

$\begin{array}{lllll}1 & 2 & 3 & 4 & 5\end{array}$
achieve at a higher level than other children.

11. I do not allow my child to get angry with me. $\begin{array}{lllllll}1 & 2 & 3 & 4 & 5\end{array}$

12. I let my child make decisions for himself $\quad \begin{array}{lllllll}1 & 2 & 3 & 4 & 5\end{array}$ or herself.

13. I feel that it is good for a child to compete $\quad \begin{array}{lllllll}1 & 2 & 3 & 4 & 5\end{array}$ with other children in academic settings.

14. I have strict, well-established rules for my child.

15. My child and I have warm, intimate times together.

16. I give my child a good many duties and $\quad \begin{array}{llllllll}1 & 2 & 3 & 4 & 5\end{array}$ family responsibilities.

17. I expect my child to impress others with $\quad \begin{array}{llllllll}1 & 2 & 3 & 4 & 5\end{array}$ his or her academic performance.

18. I believe children should not have secrets $\quad \begin{array}{llllllll}1 & 2 & 3 & 4 & 5\end{array}$ from their parents.

19. When I am angry with my child, I let him or her know it by expressing my anger verbally.

20. I teach my child that he or she is responsible for what happens to him or her.

21. I encourage my child to be independent of me.

$\begin{array}{llllllll}\text { 22. When I discipline my child it helps him } & 1 & 2 & 3 & 4 & 5\end{array}$ or her to improve.

23. I do not allow my child to question my decisions.

24. I try to keep my child away from children or families who have ideas or values that are different from our own. 
$\begin{array}{llllllll}\text { 25. I always make sure that I know where my } & 1 & 2 & 3 & 4 & 5\end{array}$ child is and what he or she is doing.

26. I believe that too much affection and tenderness can harm or weaken a child.

$\begin{array}{lllll}1 & 2 & 3 & 4 & 5\end{array}$

Finally, please answer the following questions about you and your family.

27. Are you: Asian Indian Euro-American Other (specify)

28. Is your spouse: Asian Indian Euro-American Other (specify)

29. If you are Asian Indian, what province are you or your family from:

30. Your occupation (please specify):

31. Are both spouses employed: Yes No

32. Your level of education:

33. In which country were you primarily educated:

33 . In what country do you currently reside: India United States

34. How long have you resided in this country: $1-5$ years $5-10$ years 10 or more years all my life

35. After school childcare arrangements: (for the child you have selected for the questionnaire)
a. Mother or father only
b. Grandparents, relatives or friends
c. Day care 
Appendix B

Agreement to Participate in Research

\author{
Responsible Investigator: Deepa Nutan Bhiwandker \\ Title of Protocol: Child-Rearing Practices in Asian Indians, American Asian
Indians and Euro-American Parents.
}

1. I have been asked to participate in a research study investigating the different perceptions of child rearing practices in the following groups: Asian Indians, Asian Indian immigrants in United States, second generation Asian Indians in the United States and Caucasian Americans.

2. I will be asked to complete a questionnaire based on Block's Child Rearing Practices Report at a convenient time and a convenient location. The questionnaire included 35 questions and will take approximately 10 minutes to complete.

3. There are no foreseeable risks involved in this study.

4. Since there is very little information on this topic, this study will benefit our communities by adding more knowledge about Asian Indian child rearing practices to relevant fields.

5. The results of this study may be published however there will be no information put forth that can identify me as a subject.

6. If I have any questions about this research, I may contact Deepa Bhiwandker at (408) 446-0369 or Dr. Kathryn Lindhoim at (408) 924-3752. Complaints about the research may be presented to Department Chair, Dr. Beverly Jensen at (408) 924-3711. Questions or complaints about research, subjects' rights, or research-related injury may be presented to Serena Stanford, Ph.D., Associate Academic Vice President for Graduate Studies and Research, at (408) 924-2480, if calling from Bombay India, please dial County Code 001 - (408) 924-2480.

7. If I choose not to participate in this study there will be no loss of services that I am entitled to at participating institutions. I am also aware that I may withdraw from this study at any time for any reason without jeopardizing my relationship with San Jose State University.

8. I have received a signed and dated copy of this consent form. 
- The signature of a subject on this document indicates agreement to participate in this study.

- The signature of a researcher on this document indicates agreement to include the above named subject in the research and attestation that the subject has been fully informed of his or her rights.

Subject's Signahure

Investigator's Signature
Date

Date 